\title{
Heat Transfer Characteristics of Impinging Steady and Synthetic Jets over Vertical Flat Surface
}

\author{
Xin He ${ }^{a}$, Jason Lustbader ${ }^{a^{*}}$, Mehmet Arik ${ }^{b}$, Rajdeep Sharma ${ }^{c}$ \\ ${ }^{a}$ National Renewable Energy Laboratory, Golden, Colorado, U.S.A. \\ ${ }^{\mathrm{b}}$ Department of Mechanical Engineering, Ozyegin University, Cekmekoy, Istanbul, Turkey \\ ${ }^{\mathrm{c}}$ Exponent Inc., Menlo Park, California, U.S.A.
}

\section{ABSTRACT}

In this paper, heat transfer characteristics of single-slot impinging steady and synthetic jets on a 25.4-mm $\times 25.4-$ $\mathrm{mm}$ vertical surface were experimentally investigated. The experiments were conducted with a fixed nozzle width of $1 \mathrm{~mm}$. For the steady jet study, the parameters varied in the testing were nozzle length $(4 \mathrm{~mm}, 8 \mathrm{~mm}, 12 \mathrm{~mm}$, $15 \mathrm{~mm}$ ), Reynolds (Re) number (100-2,500), and dimensionless nozzle-to-plate spacing $\left(\mathrm{H} / \mathrm{D}_{\mathrm{h}}=5,10,15,20\right)$. Correlations for average Nusselt $(\mathrm{Nu})$ number were developed to accurately predict experimental data. The heat transfer coefficient over a vertical surface increases with increasing $R e$ number. For a small nozzle-to-plate spacing $\left(\mathrm{H} / \mathrm{D}_{\mathrm{h}}=5\right)$, the average $N u$ number is not only a function of the Re number, but also a function of nozzle length. For large nozzle-to-plate spacing $\left(H / \mathrm{D}_{\mathrm{h}} \geq 10\right)$ and a nozzle length larger than $8 \mathrm{~mm}$, the heat transfer coefficient is insensitive to $\mathrm{H} / \mathrm{D}_{\mathrm{h}}$ and nozzle length. An 8-mm x 1-mm synthetic jet was studied by varying the applied voltage $(20-100 \mathrm{~V})$, frequency $(200-600 \mathrm{~Hz})$, and dimensionless nozzle-to-plate spacing $\left(\mathrm{H} / \mathrm{D}_{\mathrm{h}}=5,10\right.$, $15,20)$. Compared to the steady jet, the synthetic jet exhibited up to a $40 \%$ increase in the heat transfer coefficient. The dynamic $R e$ number was introduced to correlate heat transfer characteristics between synthetic jets and steady jets. Using the dynamic Re number collapses the synthetic and steady jet data into a single $\mathrm{Nu}$ number curve.

Keywords: Synthetic jet, steady jet, heat transfer, impingement cooling, electronics thermal management 


\section{INTRODUCTION}

Steady impinging jets have been used in a wide range of industrial processes, including steel annealing, drying of paper and textiles, and thermal management of electronic devices and power electronics. Many studies of steady jets impinging over flat and smooth surfaces have been conducted. Reviews of the experimental work on the effects of an impinging jet on heat and mass transfer characteristics were reported by Martin [1] and Jambunathan et al. [2].

Although numerous studies have been conducted to demonstrate the impact of Reynolds $(R e)$ number and nozzleto-plate spacing on local and average heat transfer characteristics of a slot nozzle impinging steady jet, $[3,4,5,6,7,8,9,10,11]$, limited information is available at low $R e$ numbers $(<2,500)$. Choo et al. [9] studied the local and average heat transfer characteristics of a micro-scale slot jet impinging on a heated flat plate. The effects of $R e$ number in the range of $150-5,000$ and nozzle-to-plate spacing of $0.5-10$ were investigated. At $\operatorname{Re}<2,500$, the heat transfer characteristics are similar for both micro-scale and macro-scale impinging slot jets, showing little sensitivity to nozzle-to-plate spacing. The study, however, was conducted using only one unconfined slot nozzle with a cross-section area of $10 \mathrm{~mm} \times 0.25 \mathrm{~mm}$. Previous studies also found that heat transfer characteristics of impinging jets also depend on the jet inlet geometry and aspect ratio $[12,13,14,15,16,17,18]$. One of the most comprehensive studies on the effect of the jet inlet geometry and aspect ratio on local and average heat transfer was conducted by Koseoglu et al. [15] using nine confined impinging jets under the same mass flow rate. The results showed heat transfer enhancement in the stagnation region when a higher aspect ratio nozzle was used. The study was conducted at a high $R e$ number $(R e=10,000)$.

The need for characterizing heat transfer at low Re numbers is in part due to emerging advanced air-cooling technology using synthetic jets to cool electronics systems. Synthetic jets have zero net mass flux because they take in and eject a high-velocity working fluid from a single opening. They do, however, have a net momentum flux, which is directed outward from the synthetic jet. The synthetic jet devices used in this study, developed by General Electric, use meso-scale piezoelectric actuators with a size on the order of centimeters to millimeters. Their characteristic Re number is dependent on the geometry and driving conditions of the synthetic jet. These synthetic jet devices are particularly well suited for small-scale electronics, such as printed circuit board components, where natural convection is not sufficient and other cooling devices, such as fans, are not practical due to space limitations. Compared to natural air convection, synthetic jets have been shown to enhance the local heat transfer coefficient by up to 15 times on a $25.4-\mathrm{mm}$ vertical square surface $[19,20,21,22]$. Compared to the steady jet, up to $40 \%$ enhancement of heat transfer coefficients have been reported with a synthetic jet [19]. However, limited analysis has been conducted to correlate impingement heat transfer characteristics between steady jets and synthetic jets. 
Motivated, in particular, by the dearth of heat transfer data at low Re numbers, a high-fidelity test rig has been developed at the National Renewable Energy Laboratory to study the impingement heat transfer on a vertical surface for both steady jets and synthetic jets. The experimental parameters include $\operatorname{Re}$ number $(\operatorname{Re}=100-2,000)$, nozzle-to-plate spacing $\left(\mathrm{H} / \mathrm{D}_{\mathrm{h}}=5-20\right)$, and nozzle aspect ratio $(\mathrm{L} / \mathrm{W}=4-15)$ at a fixed nozzle width of $1 \mathrm{~mm}$, where $\mathrm{W}$ is the nozzle width $(\mathrm{m})$, and $\mathrm{L}$ is the nozzle length $(\mathrm{m})$. A synthetic jet with a cross-section area of $8 \mathrm{~mm}$ $\times 1 \mathrm{~mm}$ was tested to develop the correlation between synthetic jet and steady jet impingement heat transfer in the low $R e$ number range.

\section{EXPERIMENTAL STUDY}

\section{Steady Jets}

Experiments were performed using an air flow test bench that both controlled and accurately measured flow rate. Figure 1 shows the schematic of the steady jet experimental setup used for this study.

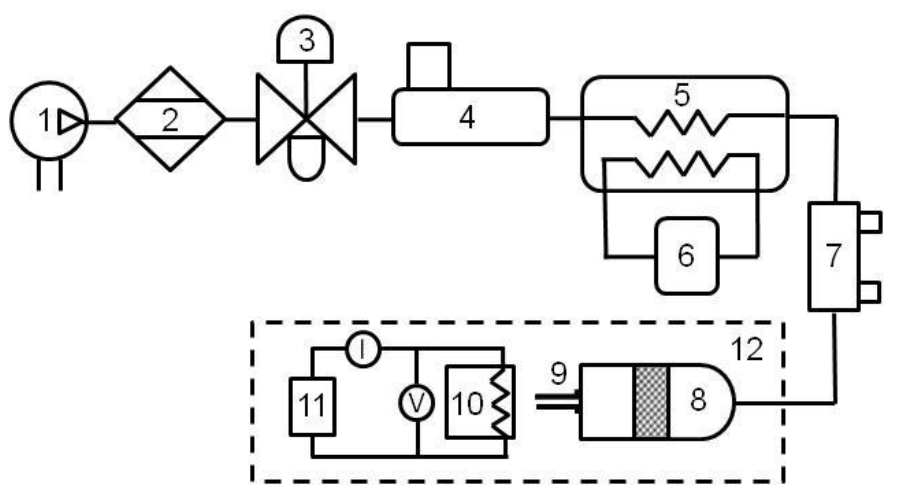

Figure 1: Schematic of the steady jet experimental setup. 1 - Compressed air, 2 - Desiccant Dryer, 3 - Filter/Regulator, 4 - Mass Flow Controller, 5 - Plate Heat Exchanger, 6 - Recirculating Bath, 7 - Laminar Flow Element, 8 - Settling Chamber, 9 - Nozzle, 10 - Heater Target, 11 - Heater Power Supply, 12 - Isolation Box

Compressed air was supplied to a desiccant dryer to remove moisture. The air was dried to a dew point of $-20^{\circ} \mathrm{C}$ or lower. It was then passed through a $5-\mu \mathrm{m}$ particulate filter and regulated to a constant pressure within the range of 68 to $137 \mathrm{kPa}$. This regulated pressure served as the source air for a mass flow controller, Sierra model C100L, which provided a range of flow from $3.3 \mathrm{~cm}^{3} / \mathrm{s}$ to $166 \mathrm{~cm}^{3} / \mathrm{s}$. The air was then passed through a plate heat exchanger for optional temperature control. Next, a laminar flow element, CME model $10\left(0-166 \mathrm{~cm}^{3} / \mathrm{s}\right)$, was used for an accurate measurement of the actual air flow rate. This was used to adjust the upstream mass flow controller set point. The air was then supplied to a settling chamber, where a honeycomb structure followed by two spaced screens straightened the flow and reduced turbulence prior to the air entering the nozzle. A calibrated T-type thermocouple was placed in the settling chamber to measure the jet air temperature. Air then exited the 
nozzle and impinged on the heat transfer target. The nozzle and target were placed within an acrylic plastic enclosure to minimize the effect of ambient air motion in the laboratory on the experiment. Heat transfer measurements were fully automated and controlled by a computer and a National Instruments data acquisition system.

Figure 2 shows a close-up view and schematic of the steady jet nozzle and heater target. Steady jet nozzles were fabricated using a rapid prototyping process. Four nozzles were tested in this study, which had the same exiting width (W) of $1 \mathrm{~mm}$ but different lengths (L) of $4 \mathrm{~mm}, 8 \mathrm{~mm}, 12 \mathrm{~mm}$, and $15 \mathrm{~mm}$. Figure 3 shows the steady jet nozzle design with exit size of $8 \mathrm{~mm} \times 1 \mathrm{~mm}$ [20]. The nozzles are designed to attach to the settling chamber base plate, using an O-ring to prevent air leakage.
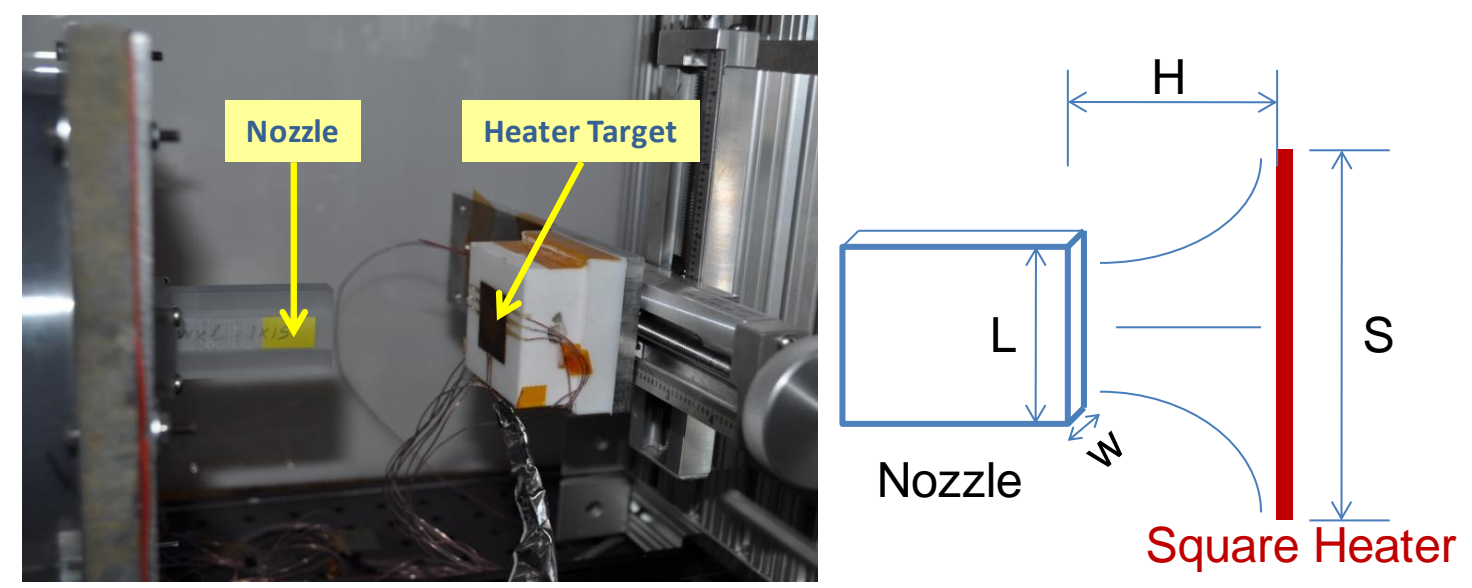

Figure 2. Picture and schematic of the steady jet nozzle test rig with horizontal orientation on a vertical target (photo: $\mathrm{Xin} \mathrm{He}$ )
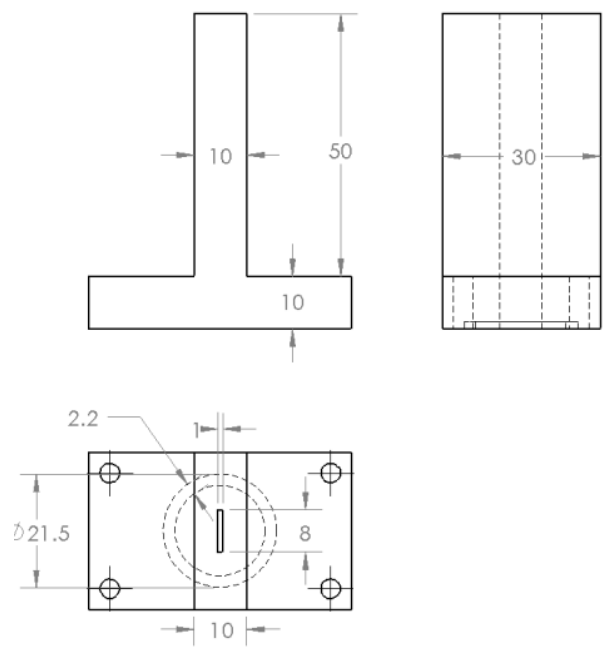

Figure 3. Steady jet nozzle design, exit size of $8 \mathrm{~mm} \times 1 \mathrm{~mm}$. 


\section{Synthetic Jets}

The synthetic jet used in this study, shown in Figure 4, was provided by General Electric Company. It has two piezoelectric actuators bonded together with an elastomeric ring applied along the entire perimeter except for a small section called the "orifice." The disks are energized with an alternating power source to actuate at a frequency in the range of 200 to $600 \mathrm{~Hz}$. This enables a bellows-like motion, allowing alternating cycles of ingestion and expulsion of air through the orifice. The lower frequency limit represents the experimentally found lowest operating frequency at which the jets start to move enough air to improve heat transfer. The present synthetic jets have a fundamental frequency of around $600 \mathrm{~Hz}$, where the disk displacement and the exit velocity reach their peak values. Any further increase in the frequency results in reduced cooling efficiency and increased power consumption. Therefore, this study was focused on the $200-600 \mathrm{~Hz}$ range. In this study, a signal generator (HP 33120A) provided a sinusoidal wave with the desired frequency and voltage, which was amplified by a power amplifier (Alpine MRP-T220) and a transformer (Radio Shack 273-1512B) before being applied to the synthetic jet. The actual power applied to the synthetic jet was monitored by a digital oscilloscope (Yokogawa DL850 ScopeCorder).
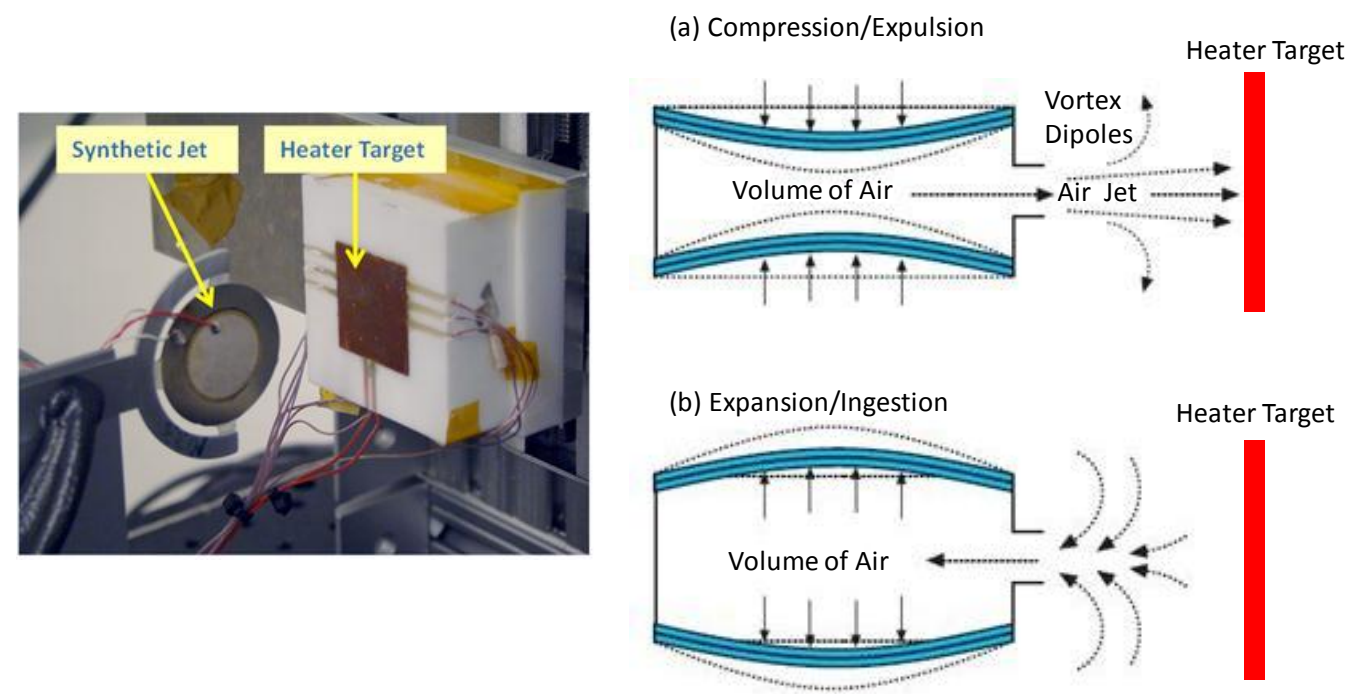

Figure 4. Close-up view of synthetic jet experimental setup and schematic of the typical operation of a synthetic jet (Xin $\mathrm{He}$ )

\section{Target Heater and Guard Heater}

The heat transfer was measured with a target heater assembly and a guard heater assembly, shown in Figure 5. The copper heat transfer surface in the target heater assembly was $25.4 \mathrm{~mm} \times 25.4 \mathrm{~mm} \times 1 \mathrm{~mm}$ thick. A 10 -watt Kapton heater (Omega KHLV-101/10) was attached to the back of the copper surface. A 0.5-mm-thick aluminum plate with the same cross-sectional dimensions was then attached to the back of the heater. These heater layers were adhered together with Arctic Silver conductive epoxy to form the target assembly. The assembly was then 
embedded in a Teflon block with the copper measurement surface flush with the exposed Teflon surface. A nonconductive epoxy was used to hold the target assembly in the Teflon. Three thermocouples were attached along the target diagonal using epoxy in machined grooves cut in the back side of the copper plate. Thermocouples were also added in groves to the back of the aluminum plate and the Teflon block to check the heater temperature and help determine steady state conditions. The target heater was powered using a DC power supply (Agilent N8740A). The target position was accurately controlled by stages.

The guard heater was used to eliminate heat transfer off the copper target and enable the measurement of heat loss to the Teflon block surrounding the target as described below. The guard heater was composed of three layers: a 10-watt Kapton heater (Omega KHLV-101/10), a $25.4 \mathrm{~mm} \times 25.4 \mathrm{~mm} \times 1 \mathrm{~mm}$ thick copper plate, and a Kapton heat flux sensor (Omega HFS-3). Three thermocouples were attached along the diagonal of the copper plate using epoxy in machined grooves cut in the back side of the copper plate. The guard heater was powered using a DC power supply (Agilent N5771A).

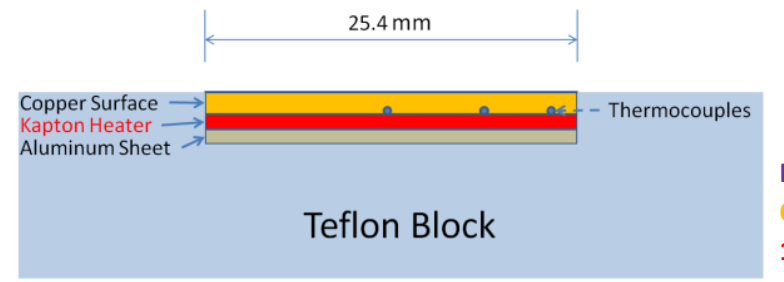

(a) Target heater assembly

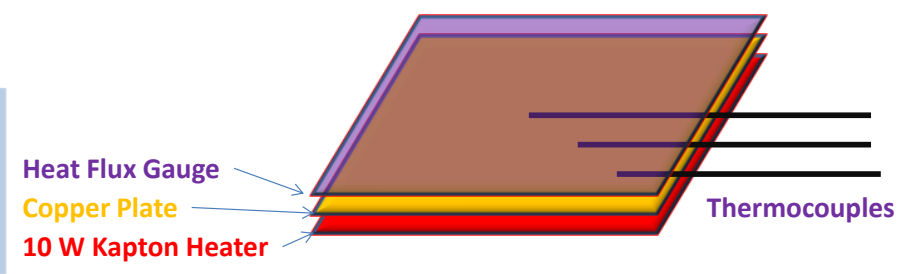

(b) Guard heater assembly

Figure 5: Schematics of the target heater and guard heater assemblies

\section{Heat Transfer Measurement}

The experimental test setup was designed and built to quantify the steady and synthetic jets heat transfer performance. Heat transfer measurements were fully automated and controlled by a data acquisition system. The steady jet air volume flow rate, synthetic jet operating conditions (parameterized by applied voltage across the piezoelectric disks and the driving frequency), heater surface temperature, and nozzle-to-plate distance were provided as inputs to the LabVIEW-based control and data acquisition system. As part of the automation, input conditions were prescribed in a sequence that enabled sequential measurements of the heat transfer performance. For the steady jet test, air flow rate was measured by the laminar flow element, which was used to adjust the mass flow controller located upstream. For the synthetic jet test, LabVIEW sent commands to the HP signal generator, which was pre-calibrated to provide the desired frequency and voltage to the synthetic jet. The target heater temperature was controlled to $57^{\circ} \mathrm{C}$ above the reference air temperature. The reference air temperature was defined for the steady jet test as the air temperature in the settling chamber and for the synthetic jet test as the ambient air temperature. At the start of each test sequence, the target assembly was pre-conditioned for 90 minutes at the first test point settings to get the entire Teflon block to reach the steady-state set point temperature. 
After pre-conditioning, each of the remaining test points took 45 minutes to reach steady state conditions. The last 5 minutes of data for each test condition were used for heat transfer calculation. The data were recorded during the whole test process at a sampling rate of $1 \mathrm{~Hz}$.

A two-step process was used to acquire heat transfer measurements from the copper target surface. The first step measured the total target assembly heat rejection $\left(Q_{\text {total }}\right)$. The second step measured the heat loss $\left(Q_{\text {loss }}\right)$ through the Teflon block. This was done by attaching the guard heater to the vertical copper heater surface using Kapton tape. The guard heater was controlled to achieve zero heat flux between the copper target surface and the guard heater. Because the heat transfer from the target copper surface is eliminated by the guard heater, the target heater power consumption is equal to the heat losses to the Teflon block, recorded as $Q_{l o s s}$. The heat transfer on the copper surface $\left(Q_{\text {surface }}\right)$ is calculated as:

$$
Q_{\text {surface }}=Q_{\text {total }}-Q_{\text {loss }}
$$

The average heat transfer coefficient on the copper surface is calculated as:

$$
\bar{h}=\frac{Q_{\text {surface }}}{A \cdot\left(T_{s}-T_{\text {air }}\right)}
$$

where $A$ is the target heated wetted surface area $\left(\mathrm{m}^{2}\right), T_{s}$ is the target heated wetted surface temperature calculated by averaging the temperatures measured by the three thermocouples attached along the target diagonal in the back side of the copper plate $\left({ }^{\circ} \mathrm{C}\right)$, and $T_{a i r}$ is the air temperature in the settling chamber for steady jet or the ambient air temperature for the synthetic jet $\left({ }^{\circ} \mathrm{C}\right)$.

The average Nusselt $(\bar{N} \bar{u})$ number is calculated as:

$$
\overline{N u}=\frac{\bar{h} \cdot D_{h}}{k}
$$

where $\bar{h}$ is the average heat transfer coefficient $\left(\mathrm{W} / \mathrm{m}^{2}-\mathrm{K}\right)$, calculated using Eq. (2), $D_{h}$ is the jet nozzle hydraulic diameter $(\mathrm{m})$, and $k$ is the air thermal conductivity $(\mathrm{W} / \mathrm{m}-\mathrm{K})$.

\section{EXPERIMENTAL UNCERTAINTY}

Major sources of uncertainty for the experiments were identified as the heat losses through the heater holder, temperature measurements, heater power, and velocity measurements. As mentioned before, a set of separate heat loss experiments was performed for the heaters to quantify the heat losses through the substrate. This was done with a guard heater. During data reduction, the heat loss, measured with a guarded heater test, was subtracted from total power supplied into the heater. Another source of uncertainty was the temperature measurements. T- 
type thermocouples were calibrated using an isothermal bath and reference probe, achieving a $\mathrm{U}_{95}$ uncertainty of $\pm 0.1^{\circ} \mathrm{C}$.

Table 1 summarizes the uncertainties calculated based on the procedures given in [23]. The largest uncertainty was found to be in the average $N u$ number calculation due to the propagation of uncertainties from power measurements, volumetric air flow rate, velocity measurement, and nozzle size measurement. Uncertainty in the velocity measurement is strongly influenced by the placement of the hot-wire probe at the jet exit. The hot-wire probe was positioned to within $\pm 0.1 \mathrm{~mm}$ using automated stages. Fluid properties for the $\mathrm{Nu}$ and $\mathrm{Re}$ numbers were calculated using average measured temperatures, and uncertainties were propagated.

Table 1: Uncertainties in the experimental measurements, $\mathrm{U}_{95}$

\begin{tabular}{|l|l|}
\hline T-type thermocouples $[\mathrm{K}]$ & 0.2 \\
\hline Heater power measurement & $4.1 \%$ \\
\hline Jet exit velocity & $4 \%$ \\
\hline Hydraulic diameter & $8.8 \%$ \\
\hline Average $\mathrm{Nu}$ number & $10 \%$ \\
\hline Re number & $13.5 \%$ \\
\hline Heat transfer coefficient & $4.4 \%$ \\
\hline
\end{tabular}

\section{RESULTS AND DISCUSSIONS}

\section{Steady Jet Heat Transfer}

Four different nozzles $(4 \mathrm{~mm} \times 1 \mathrm{~mm}, 8 \mathrm{~mm} \times 1 \mathrm{~mm}, 12 \mathrm{~mm} \times 1 \mathrm{~mm}, 15 \mathrm{~mm} \times 1 \mathrm{~mm})$ were tested at four nozzleto-plate distances $\left(H / D_{h}=5,10,15,20\right)$. Figure 6 shows the variation of the average heat transfer coefficient as a function of the Re number and nozzle geometry at each $\mathrm{H} / \mathrm{D}_{\mathrm{h}}$. In this section, the Re number is calculated as:

$$
\overline{\operatorname{Re}}_{\text {SteadyJet }}=\frac{\bar{V}_{\text {SteadyJet }} \cdot D_{h}}{v}
$$

where $\bar{V}_{\text {SteadyJet }}$ is the average air velocity $(\mathrm{m} / \mathrm{s})$ calculated based on the volumetric flow rate and nozzle exit area, and $v$ is the gas kinematic viscosity $\left(\mathrm{m}^{2} / \mathrm{s}\right)$.

The heat transfer coefficient increases with the $R e$ number and nozzle size. For $\mathrm{H} / \mathrm{D}_{\mathrm{h}}=5$, nozzle geometry has a significant impact on the heat transfer coefficient. The impact of the nozzle geometry diminishes with increasing $H / D_{h}$. For $H / D_{h} \geq 10$, the heat transfer coefficient is relatively insensitive to nozzle geometry if the nozzle length is larger than $8 \mathrm{~mm}$. The $4-\mathrm{mm} \times 1-\mathrm{mm}$ nozzle exhibits the lowest heat transfer coefficient at all $\mathrm{H} / \mathrm{D}_{\mathrm{h}}$ because it has the lowest mass air flow at the same $R e$ number. 

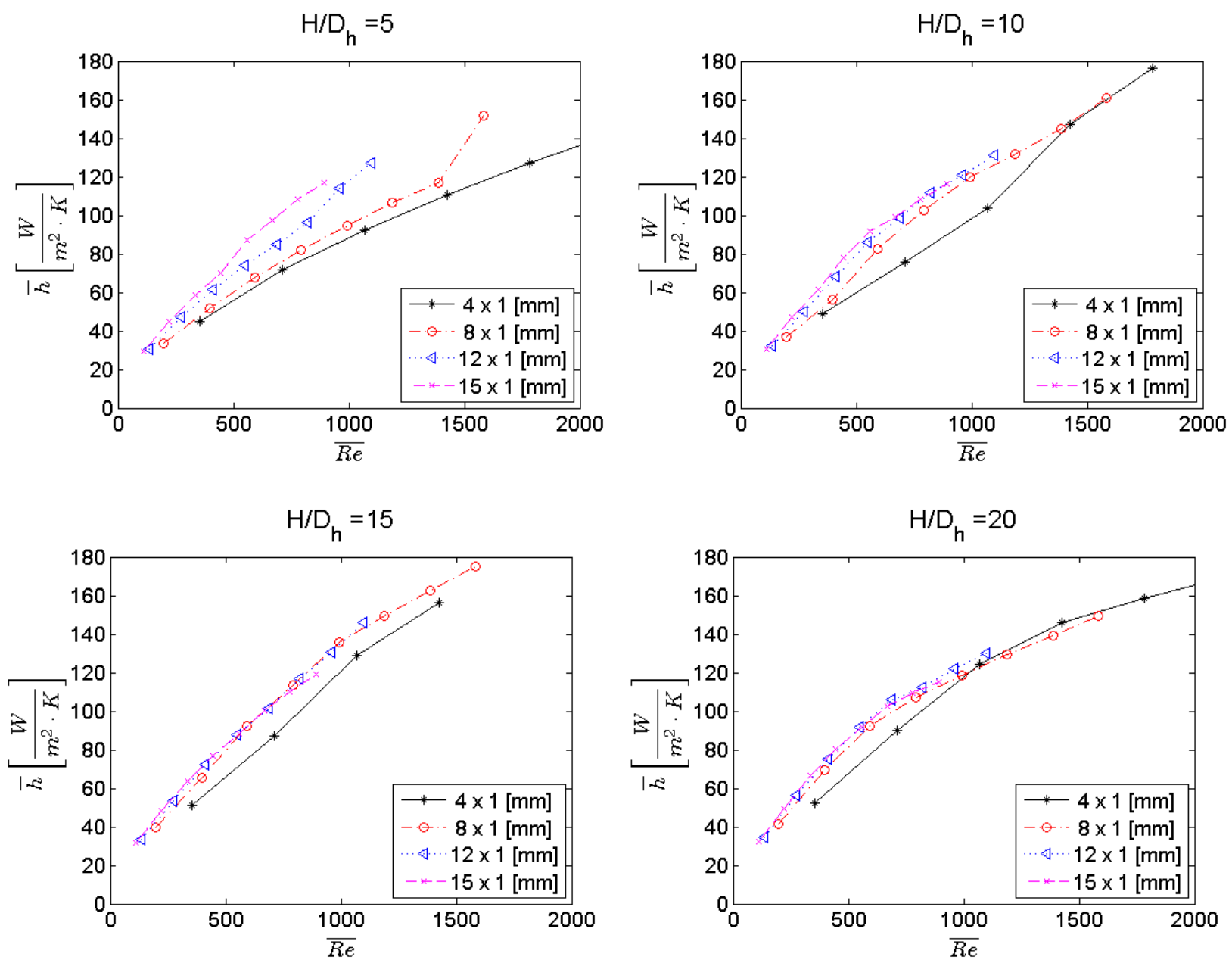

Figure 6. Variation of heat transfer coefficient with $\overline{R e}$, nozzle geometry, and nozzle-to-plate spacing

The experimental results were compared with the empirical correlation developed by Choo et al. [9], shown in Figure 7. Note that the definition of $\mathrm{Nu}$ in Choo's correlation was based on the nozzle width (W), not the nozzle hydraulic diameter $(\mathrm{Dh})$. Thus, $\overline{\mathrm{Nu}}$ presented in Figure 7 is defined using the following equation:

$$
\overline{N u}_{W}=\frac{\bar{h} \cdot W}{k}
$$

In the study conducted by Choo et al., the nozzle length is the same as the heater length. In this work, four difference nozzle lengths were studied, all of which are shorter than the copper target surface length (25.4 mm). Because Choo et al.'s empirical correlation does not consider the impacts of nozzle length and target surface size, the authors do not expect a perfect match between the experimental results and the predicted results by the empirical correlation. Overall, the 15-mm $\times 1-\mathrm{mm}$ nozzle results best match the correlation with a mean difference less than $7 \%$ and a maximum difference less than $30 \%$. This is because the ratio of the nozzle length 
$(15 \mathrm{~mm})$ to the heated surface length $(25.4 \mathrm{~mm})$ is the closest to that of Choo et al.'s setup. It is not surprising to find that the difference increases with reducing nozzle length. For the 4-mm $\times 1$-mm nozzle, the correlation overpredicts the $N u$ number by an average of $66 \%$ with a maximum difference of $135 \%$.

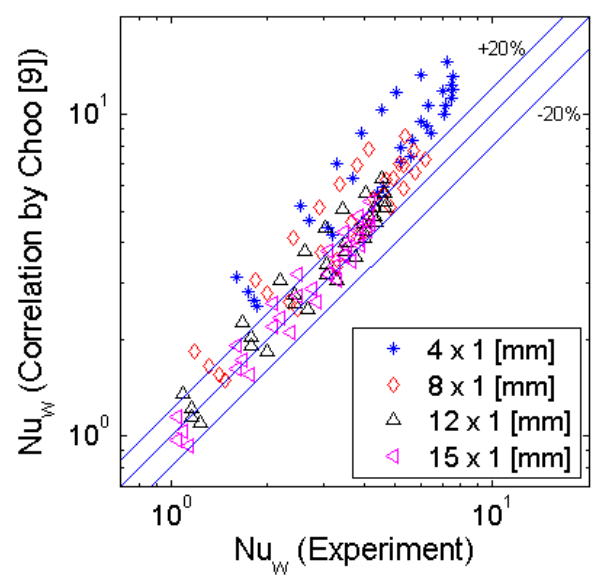

Figure 7. Comparison of the $N u_{w}$ number between correlation from Choo et al. [9] and experimental results from this work For large nozzle-to-plate spacing $\left(\mathrm{H} / \mathrm{D}_{\mathrm{h}} \geq 10\right)$, the variation of heat transfer coefficients for nozzles $8 \mathrm{~mm} \times 1 \mathrm{~mm}$, $12 \mathrm{~mm} \times 1 \mathrm{~mm}$, and $15 \mathrm{~mm} \times 1 \mathrm{~mm}$ are reorganized and presented in Figure 8. This shows that for $\mathrm{L} / \mathrm{W} \geq 8$ and $\mathrm{H} / \mathrm{D}_{\mathrm{h}} \geq 10$, the heat transfer coefficient is insensitive to both nozzle geometry and nozzle-to-plate spacing. For $R e$ $>1,000$, the heat transfer coefficient is slightly higher when $\mathrm{H} / \mathrm{D}_{\mathrm{h}}=15$. Overall, the correlation for the average heat transfer coefficient $\left(\mathrm{L} / \mathrm{W} \geq 8, \mathrm{H} / \mathrm{D}_{\mathrm{h}} \geq 10, R e<1,600\right)$ has the following form $\left(\mathrm{R}^{2}=0.94\right)$ :

$$
\bar{h}_{\text {Ave }}=1.35 *\left(\overline{\operatorname{Re}}_{\text {SteadyJet }}\right)^{0.655}
$$

The average $N u$ number can be calculated as:

$$
\overline{N u}=1.35 *\left(\overline{\operatorname{Re}}_{\text {SteadyJet }}\right)^{0.655} \cdot \frac{D_{h}}{k}
$$

Figure 9 compares the $N u$ number calculated using Eq. (7) with the experimental results. The differences are within $\pm 15 \%$, indicating that the correlation represents the heat transfer characteristics within the tested range well. 

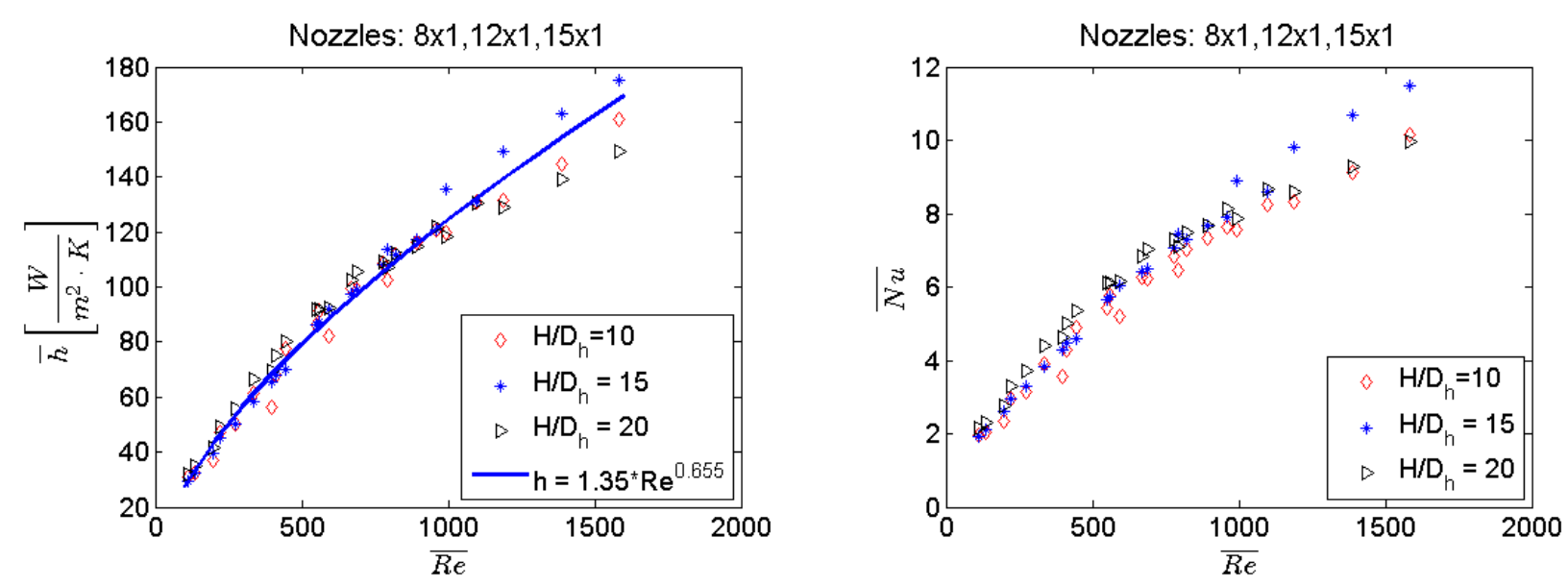

Figure 8. Variation of average heat transfer coefficient and $\overline{N u}$ with $\overline{R e}$, nozzle geometry $(\mathrm{L} / \mathrm{W}=8$, 12, 15), and nozzle-to-plate spacing $\left(H / D_{h}=10,15,20\right)$

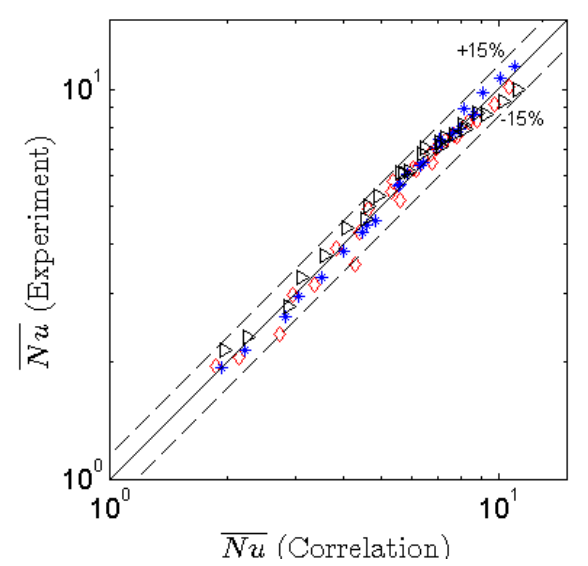

Figure 9. Comparison between the average $N u$ number obtained from $\mathrm{Eq}$. (7) and that from experimental results with $\mathrm{L} / \mathrm{W} \geq 8$, $\mathrm{H} / \mathrm{D}_{\mathrm{h}} \geq 10, \operatorname{Re}<1,600$

For small nozzle-to-plate spacing $\left(\mathrm{H} / \mathrm{D}_{\mathrm{h}}=5\right)$, the nozzle geometry has a significant impact on the average heat transfer coefficient. Figure 10 shows the variation of the average $N u$ number with $R e$ number and nozzle geometry. Here, a correlation was developed by adopting the correlation recommended by Choo et al. [9], but incorporating an exponent term (m) for the Re number, as recommended by Martin [1]. The average $N u$ number at low nozzle-to-plate spacing $\left(\mathrm{H} / \mathrm{D}_{\mathrm{h}}=5\right)$ has the following form:

$$
\overline{N u}=0.0784 * \overline{\operatorname{Re}}^{m}\left(\frac{H}{D_{h}}\right)^{-0.15} \cdot\left[a+b \cdot \frac{L}{S}+c \cdot\left(\frac{L}{S}\right)^{2}\right]
$$

where

$$
m=0.695-\left[\left(\frac{S}{4 \cdot W}\right)+\left(\frac{H}{2 \cdot W}\right)^{1.33}+3.06\right]^{-1},
$$


$S$ is the width of the heater surface $(\mathrm{m}), W$ is the nozzle width $(\mathrm{m})$, and $L$ is the nozzle length $(\mathrm{m})$, as shown in Figure 2.

A second-order polynomial term is included to represent the effect of nozzle geometry. Constants $a, b$, and $c$ are solved in a least-squares sense based on the experimental data, where $a=0.826, b=0.928$, and $c=0.742$.

Figure 10 also shows the $N u$ number predicted by Eq. (8). The correlation of the average $N u$ number matches very well with the experimental results to within $\pm 10 \%$, as shown in Figure 11 .

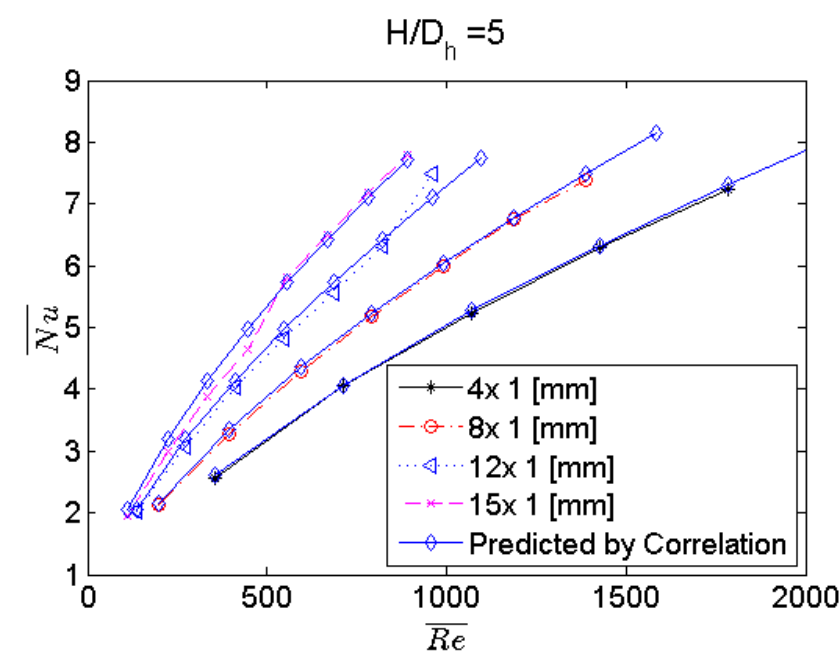

Figure 10. Variation of $\mathrm{Nu}$ number with $R e$ number and nozzle geometry $\mathrm{H} / \mathrm{D}_{\mathrm{h}}=\mathbf{5}$

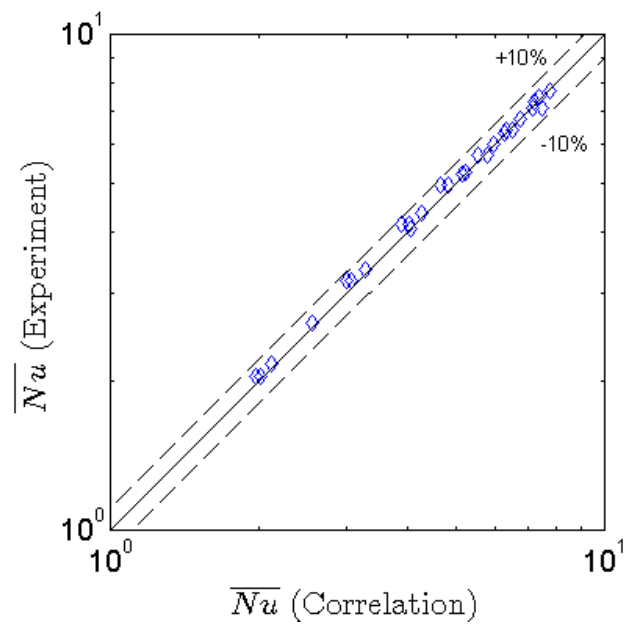

Figure 11. Comparison between the average $\mathrm{Nu}$ number obtained from Eq. (8) and that from experimental results $\mathbf{H} / \mathrm{D}_{\mathrm{h}}=\mathbf{5}$

The different heat transfer behavior exhibited by varying the nozzle-to-plate spacing could be attributed to the jet spreading and air entrainment. For small nozzle-to-plate spacing, less spreading and entrainment can cause "dead zones" at the four corners of the heater. With increasing nozzle length, a larger heater area is influenced by the air 
flow, reducing the size of these "dead zones" and thus increasing the effective heat transfer coefficient. For a large nozzle-to-plate spacing, spreading and entrainment result in more uniform coverage of the target, reducing sensitivity to the nozzle length. For the longer nozzles and/or higher $H / \mathrm{D}_{\mathrm{h}}$, part of the jet might be "wasted" by not directly impinging on the heater surface. Future studies should consider quantifying the Reynolds number along the plate (or normal to the jet direction), which could provide a more in-depth explanation of the effect of $\mathrm{H} / \mathrm{Dh}$ on heat transfer. In this study, the average heat transfer coefficient is insensitive to the nozzle length at $H / \mathrm{D}_{\mathrm{h}}$ $\geq 10$ and $\mathrm{L} \geq 8 \mathrm{~mm}$. For the limited $\mathrm{H} / \mathrm{D}_{\mathrm{h}}$ cases studied, the best heat transfer was found to occur at $\mathrm{H} / \mathrm{D}_{\mathrm{h}}=10$.

\section{Synthetic Jet Heat Transfer}

\section{Velocity Measurement}

For the steady jet, $\bar{V}_{\text {SteadyJet }}$, which can be easily calculated based on the flow rate and nozzle exit area, was used as the characteristic velocity for the Re number calculation. For the synthetic jet, however, gas velocity changes with time. The synthetic jet time-averaged mean gas velocity, which is similar to $\bar{V}_{\text {SteadyJet }}$ of the steady jet, cannot be easily measured, especially in a non-confined space. Mapping the nozzle exit flow field using a hotwire anemometer is extremely time consuming because flow velocities change with the applied voltage and frequency. Even with the fully mapped flow field near the nozzle exit, it is still hard to separate the airflow induced by nozzle expulsion from the ambient air entrainment flow near the nozzle edge. A more reliable approach is to define the $R e$ number based on the synthetic jet time-averaged maximum gas velocity $\left(V_{\text {SynJet_Max }}\right)$. For an equivalent comparison between the synthetic jet and the steady jet, the maximum steady jet gas velocity, $V_{\text {SteadyJet_Max }}$, is used as the characteristic velocity for the steady jet $R e$ number calculation. In this study, only an $8-\mathrm{mm} \times 1-\mathrm{mm}$ synthetic jet was tested.

Jet exit velocity measurements were taken using a TSI IFA300 constant-temperature hot-wire anemometer system with a TSI 1250A single-axis hot wire probe. The sensing element length was $1.27 \mathrm{~mm}$ with a diameter of 3.8 $\mu \mathrm{m}$. The sensor was parallel to the long axis of the nozzle exit and to the nozzle surface. The measurement position was controlled with automated stages with a minimum step of $0.00635 \mathrm{~mm}$. The hot wire was calibrated prior to each test day using a TSI 1128 velocity calibrator.

For the steady jet, the sampling rate for velocity measurement was set at $1 \mathrm{kHz}$. The hot wire probe was positioned within $1 \mathrm{~mm}$ of the jet orifice. Nozzle exit velocities were measured along the short axis of the nozzle exit with a step of $0.127 \mathrm{~mm}$. Figure 12(a) shows the measurement results for the 8 - $\mathrm{mm} \times 1$-mm steady jet nozzle at eight different nozzle volumetric flow rates. The markers in the figure represent the experimental data. The velocity $V_{\text {SteadyJet_Max }}$ was then calculated by finding the maximum value of the cubic spline fit of the 
experimental data at each volumetric flow rate. Figure 12 (b) shows the variation of $V_{\text {SteadyJet_Max }}$ and $\bar{V}_{\text {SteadyJet }}$ as a function of the steady jet flow rate. Similar to $\bar{V}_{\text {SteadyJet }}, V_{\text {SteadyJet_Max }}$ increases linearly with the jet flow rate, which is about $75 \%$ higher than $\bar{V}_{\text {SteadyJet }}$.
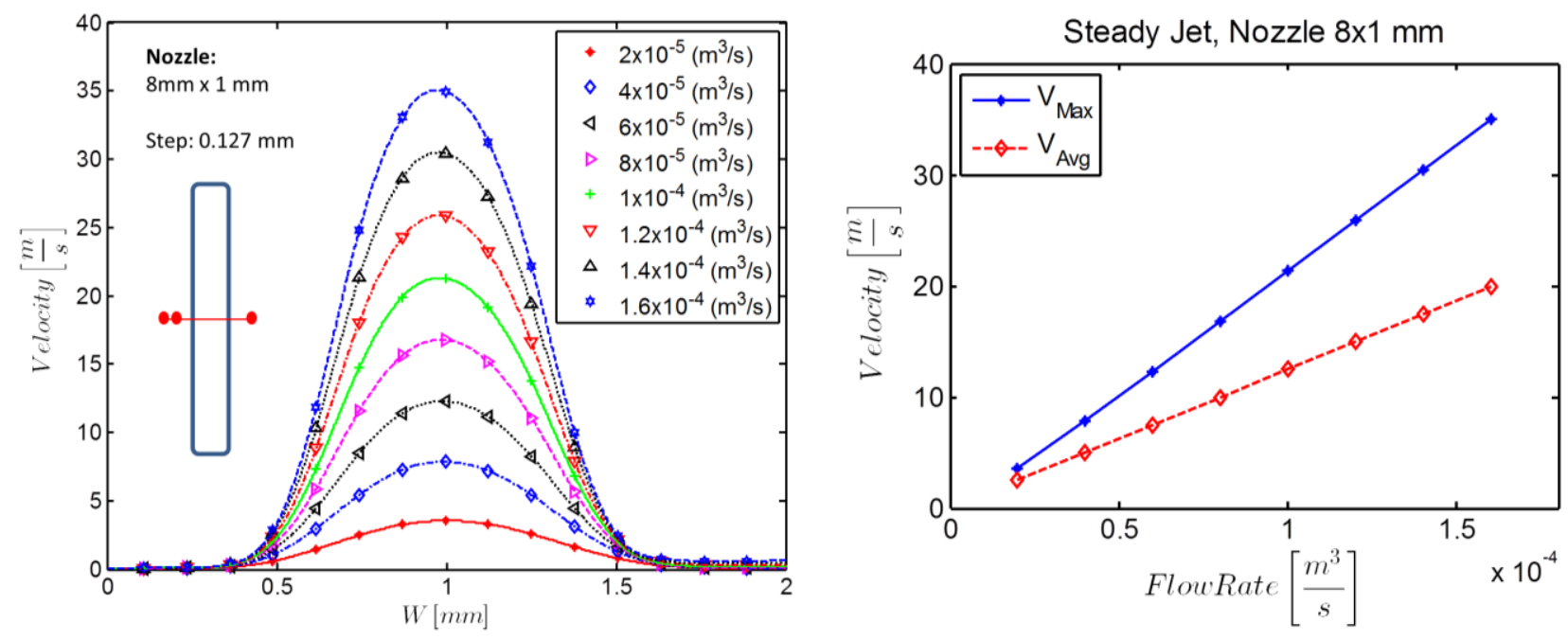

Figure 12. Nozzle exit velocity for 8-mm $\times 1-\mathrm{mm}$ steady jet nozzle

The steady jet Re number, calculated based on the maximum gas velocity, is defined as:

$$
\operatorname{Re}_{\text {SteadyJet_Max }}=\frac{V_{\text {SteadyJet_Max }} \cdot D_{h}}{v}
$$

Similar to the steady jet gas velocity measurement, synthetic jet gas velocities were measured by positioning the hot-wire probe within $1 \mathrm{~mm}$ of the synthetic jet orifice. The velocities along the short axis of the nozzle exit were measured with the position step of $0.127 \mathrm{~mm}$. The sampling rate was set at $100 \mathrm{kHz}$, which is adequate to capture the dynamic nature of the synthetic jet gas flow.

Figure 13(a) shows the instantaneous synthetic jet gas velocities as a function of time at 18 locations along the short axis of the nozzle exit. The synthetic jet was operated at $100 \mathrm{~V}$ and $600 \mathrm{~Hz}$. Figure 13(b) shows the maximum flow velocity observed at the synthetic jet exit. During the actuator ejection stroke, the instantaneous peak gas velocity, $V_{\text {SynJet_Peak }}$, is found to be greater than $50 \mathrm{~m} / \mathrm{s}$. During the suction stroke, the instantaneous velocity is much lower than the ejection stroke with peak velocity of about $12 \mathrm{~m} / \mathrm{s}$.

Because only the ejection stroke will contribute to cooling of the target surface, the suction stroke is excluded in the calculation of $V_{\text {SynJet_Max }}$, which is defined as: 


$$
V_{\text {SynJet_Max }}=\frac{1}{t_{\text {total }}} \int_{0}^{t_{\text {jection }}} V_{\text {Max }}(t) d t
$$

where $V_{M a x}$ is the maximum gas velocity observed at the synthetic jet exit, as shown in Figure 13 (b), $t_{\text {ejection }}$ is the time duration of the ejection stroke, and $t_{\text {total }}$ is the duration of full synthetic jet flow cycle.

Figure 14 shows the variations of $V_{\text {SynJet_Peak }}$ and $V_{\text {SynJet_Max }}$ with the applied voltage and frequency. Both velocities increase monotonically with increasing voltage and frequency. $V_{\text {SynJet_Peak }}$ is about three times higher than $V_{\text {SynJet_Max. }}$

The characteristic synthetic jet $R e$ number describing the exit flow is defined as:

$$
\operatorname{Re}_{\text {SynJet_Max }}=\frac{V_{\text {SynJet_Max }_{-}} \cdot D_{h}}{v}
$$

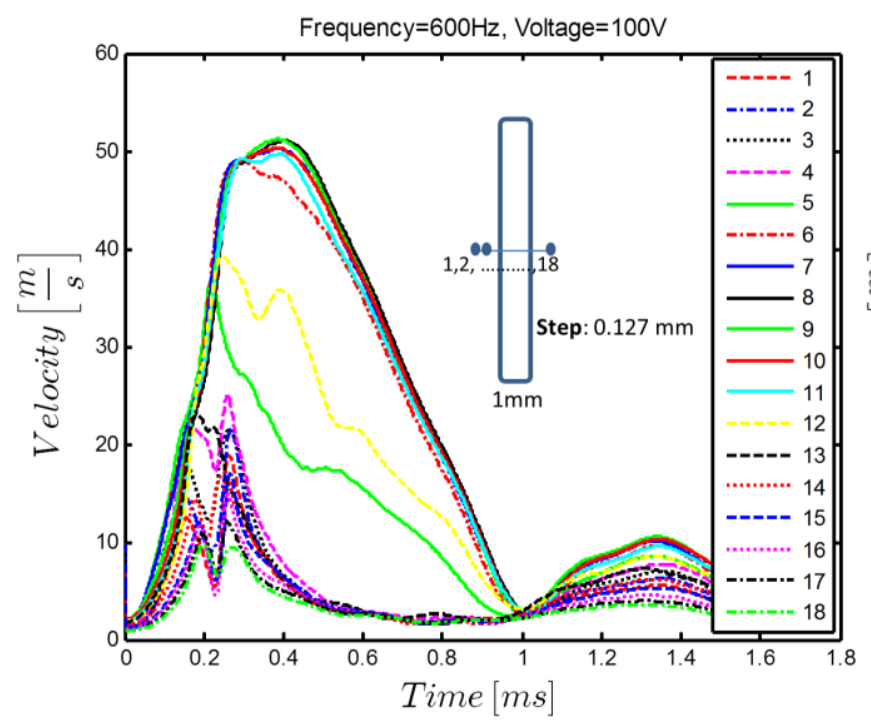

(a)

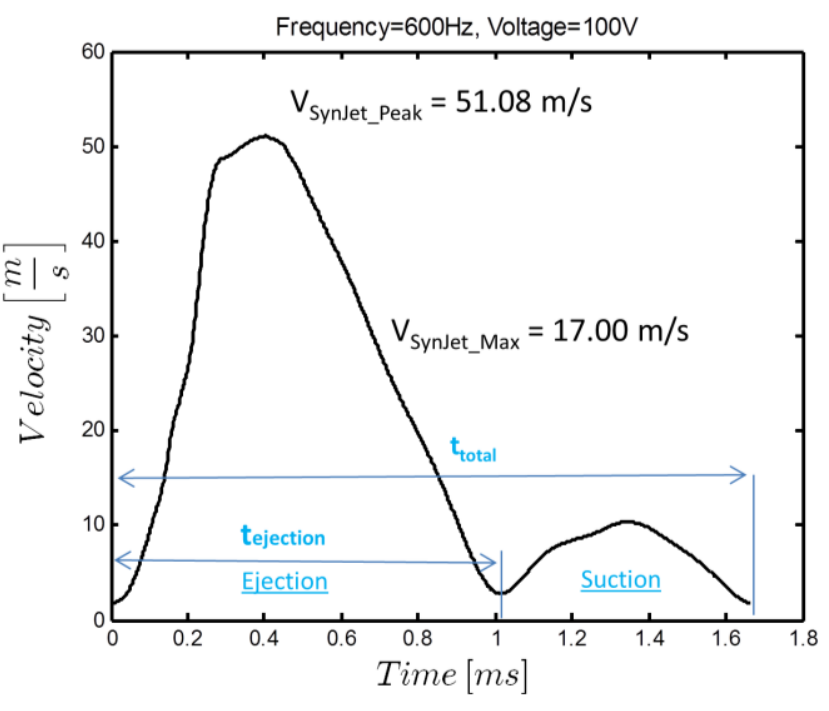

(b)

Figure 13. Instantaneous jet exit velocities for $8-\mathrm{mm} \times 1-\mathrm{mm}$ synthetic jet at $100 \mathrm{~V}$ and $600 \mathrm{~Hz}$ 

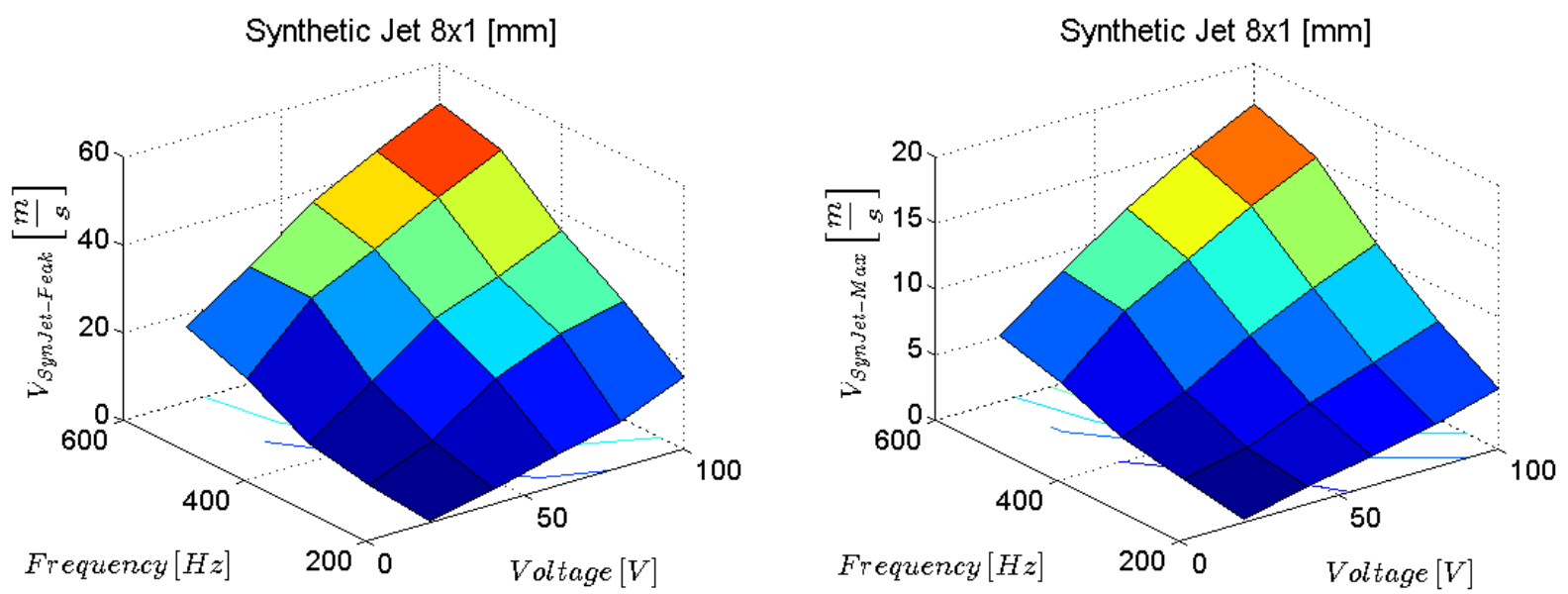

Figure 14. Variation of $V_{\text {SynJet_Peak }}$ and $V_{\text {SynJet_Max }}$ with the applied voltage and frequency

\section{Synthetic Jet Heat Transfer}

Figure 15 shows the variation of the synthetic jet $N u$ number with the characteristic $R e$ number, jet operating frequency, and nozzle-to-plate spacing. The steady jet results are also included in the figure for comparison. For small nozzle-to-plate spacing $\left(\mathrm{H} / \mathrm{D}_{\mathrm{h}}=5\right)$, the $N u$ number tends to increase with jet frequency. Compared to the steady jet, the synthetic jet exhibits a $40 \%$ enhancement of heat transfer. At large nozzle-to-plate spacing $\left(H / D_{h} \geq\right.$ 10), jet frequency has little impact on the $N u$ number. The difference between the synthetic jet and the steady jet tends to diminish with increasing $\mathrm{H} / \mathrm{D}_{\mathrm{h}}$. At $\mathrm{H} / \mathrm{D}_{\mathrm{h}}=10$, the $N u$ numbers of the synthetic jet are about $30 \%$ higher than those of the steady jet. This differential between the synthetic and steady jet reduces to $20 \%$ at $\mathrm{H} / \mathrm{D}_{\mathrm{h}}=15$ and $15 \%$ at $H / D_{h}=20$. This is not surprising as the dynamic feature of the synthetic jet tends to dissipate with increasing distance between the nozzle and heater surface. For the synthetic jet, the best heat transfer performance is observed at $\mathrm{H} / \mathrm{D}_{\mathrm{h}}=10$. For the steady jet, the best heat transfer performance is observed at $\mathrm{H} / \mathrm{D}_{\mathrm{h}}=15$. 

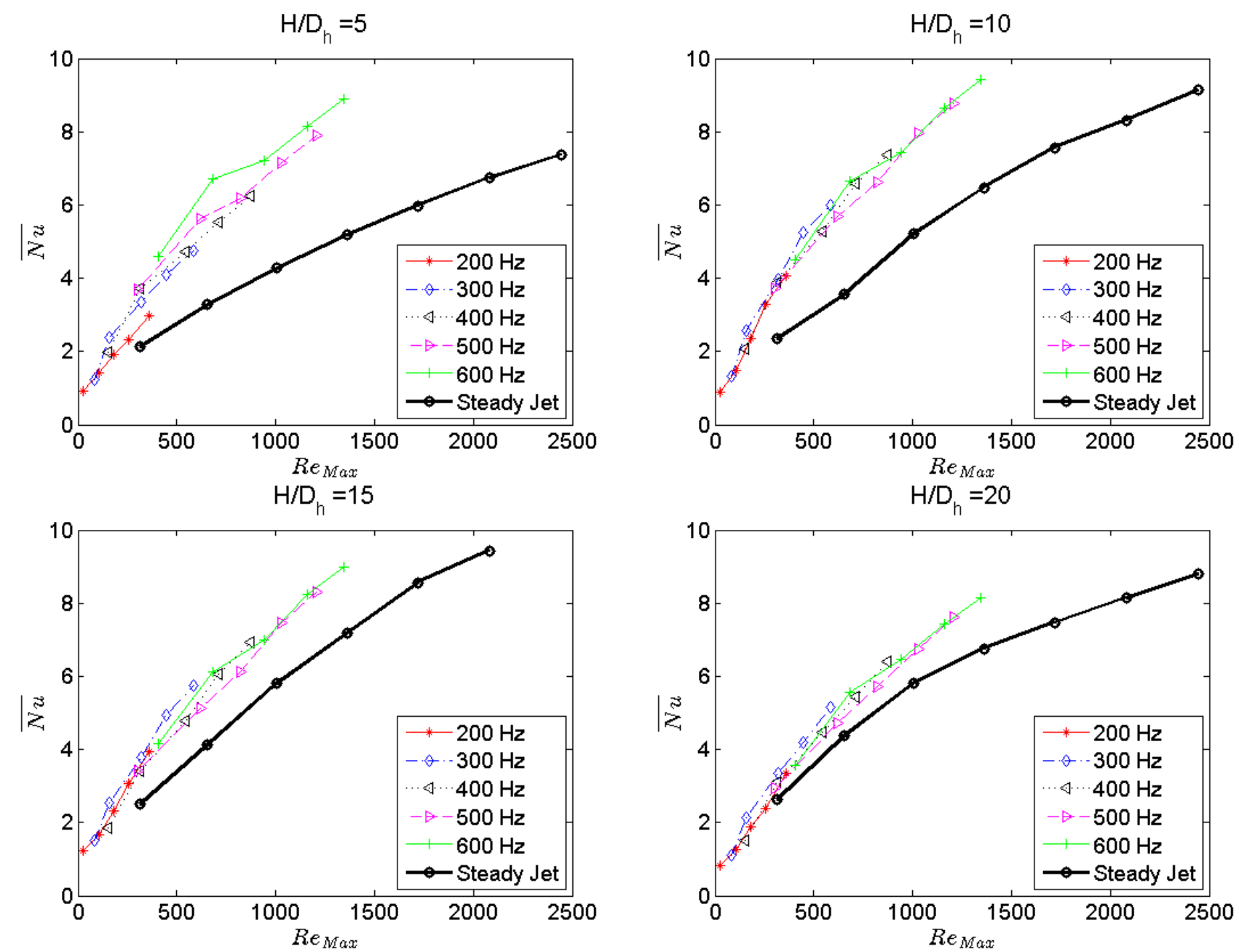

Figure 15. Variation of $\mathrm{Nu}$ number with $R e$ number and nozzle frequency (nozzle: $8 \mathrm{~mm} \times 1 \mathrm{~mm}$ )

\section{Correlating Steady Jet and Synthetic Jet Heat Transfer}

Zeng and Assanis [24] conducted dimensional analysis on unsteady convective heat transfer in an internal combustion engine intake manifold. Based on the analysis, Zeng and Assanis used a dynamic correction term and introduced a dynamic Re number to develop the unsteady heat transfer models for the heat transfer process in the internal combustion engine intake manifold. The same analysis can be applied to the impingement heat transfer on a vertical surface.

The momentum equation for the unsteady boundary layer (shown in Fig. 16) can be written as:

$$
\frac{\partial u}{\partial t}+u \frac{\partial u}{\partial x}+v \frac{\partial u}{\partial y}=v \frac{\partial^{2} u}{\partial y^{2}}
$$




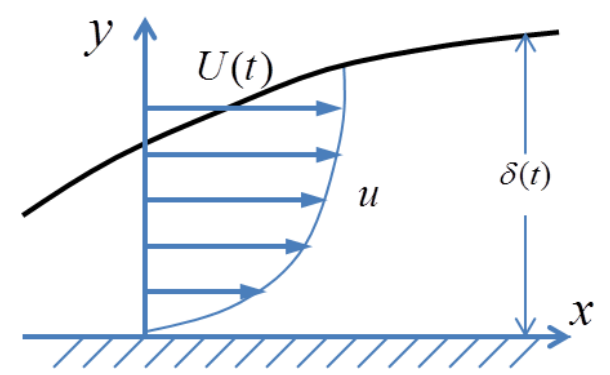

Figure 16. Unsteady momentum boundary layer

Normalizing Eq. (11) using the following dimensionless variables:

$$
\begin{gathered}
u^{*}=u / U, v^{*}=v / U, \text { where } U=U(t) \\
u^{*}=x / D_{h}, v^{*}=y / D_{h} \\
t^{*}=t /\left(D_{h}{ }^{2} / \alpha\right)=\text { Fourier number }
\end{gathered}
$$

The normalized momentum equation can be expressed as:

$$
\left[\frac{D_{h}}{U^{2}} \frac{d U}{d t}\right] u^{*}+\frac{1}{\operatorname{Re} \cdot \operatorname{Pr}} \frac{\partial u^{*}}{\partial t^{*}}+u^{*} \frac{\partial u^{*}}{\partial x^{*}}+v^{*} \frac{\partial u^{*}}{\partial y^{*}}=\frac{1}{\operatorname{Re}} \frac{\partial^{2} u^{*}}{\partial y^{* 2}}
$$

In addition to the Re number and the Prandtl number, a third dimensionless variable that is related to the unsteady boundary layer is introduced as:

$$
\Pi=\frac{D_{h}}{U^{2}} \frac{d U}{d t}=\frac{\rho \frac{d U}{d t}}{\rho U \frac{U}{D_{h}}}=\frac{\text { temporal gradient of inertial force }}{\text { spatial gradient of inertial force }}
$$

Zeng and Assanis [24] introduced dynamic velocity using the dimensionless variable defined as:

$$
U_{d y n}=U\left[1+C \frac{D_{h}}{U^{2}} \frac{d U}{d t}\right]
$$

where $C$ is a calibration constant determined experimentally.

The analysis above was conducted based on the air velocity near the heat transfer surface. In this study, however, the velocity was measured at the nozzle exit. Here, a fourth dimensionless correction term $\frac{H}{D_{h}}$ was introduced to represent the dynamic velocity dissipation impacted by nozzle-to-plate spacing. For jet impingement heat transfer, the authors introduce dynamic velocity as: 


$$
V_{d y n}=V_{\text {SynJet_Max }} \cdot\left[1+C_{1} \frac{D_{h}}{V_{\text {SynJet_Max }}^{2}}\left(\frac{d V_{\text {Max }}}{d t}\right)_{\text {Max }}\left(\frac{D_{h}}{H}\right)^{C_{2}}\right]
$$

where $\left(\frac{d V_{\text {Max }}}{d t}\right)_{\text {Max }}$ is the maximum changing rate of velocity, and $C_{l}$ and $C_{2}$ are constants determined based on the experimental data to give the best agreement between steady jet and synthetic jet heat transfer coefficients.

The result shows that $C_{2}$ is very close to 1 . To simplify the unsteady correction term, $C_{2}$ is selected to be equal to 1 and $C_{l}$ is recalculated. The following correlation best represents the dynamic $R e$ number:

$$
\operatorname{Re}_{d y n}=\operatorname{Re}_{\text {SynJet_Max }} \cdot\left[1+22.4 \cdot \frac{D_{h}}{V_{\text {SynJet_Max }^{2}}^{2}} \cdot\left(\frac{d V_{\text {Max }}}{d t}\right)_{\text {max }} \cdot \frac{D_{h}}{H}\right]
$$

Figure 16 shows the variation of the $N u$ number with the dynamic $R e$ number for both synthetic jets and steady jets. By introducing the dynamic correction term, the synthetic jet $N u$ number collapses to the steady jet $N u$ number.
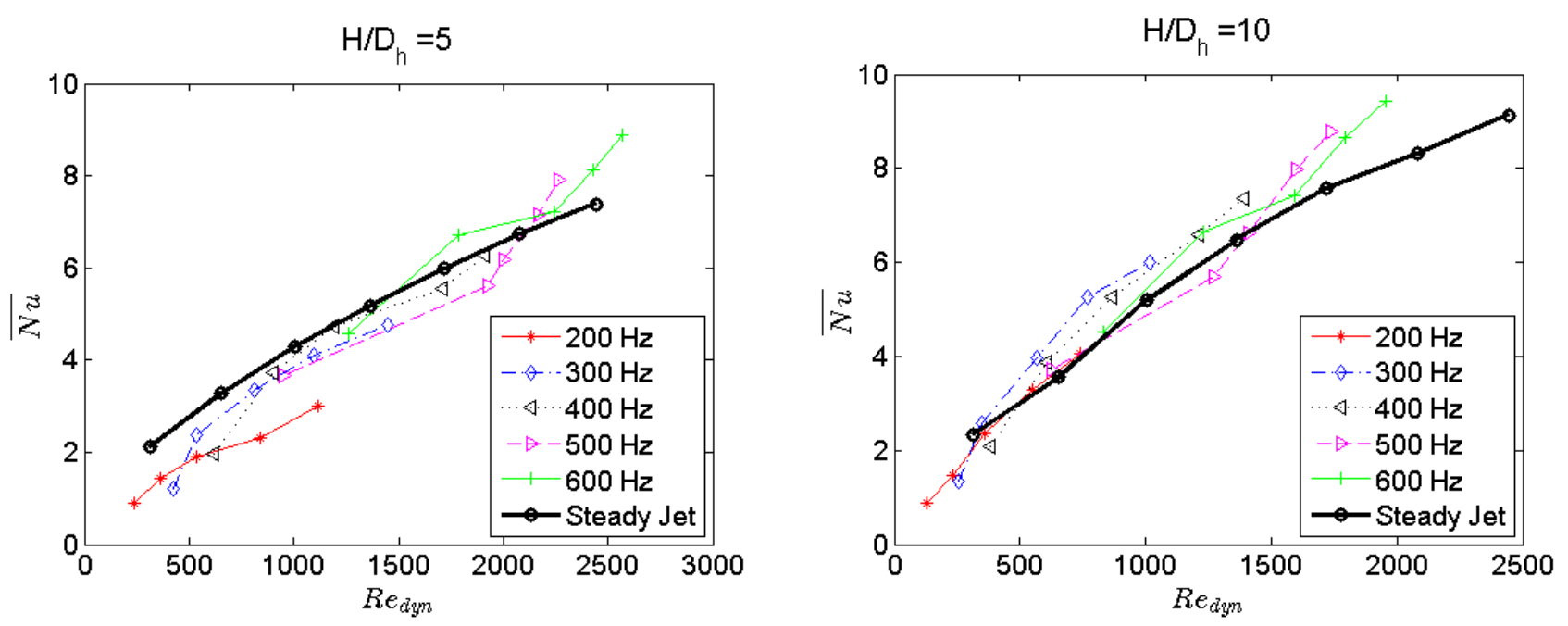

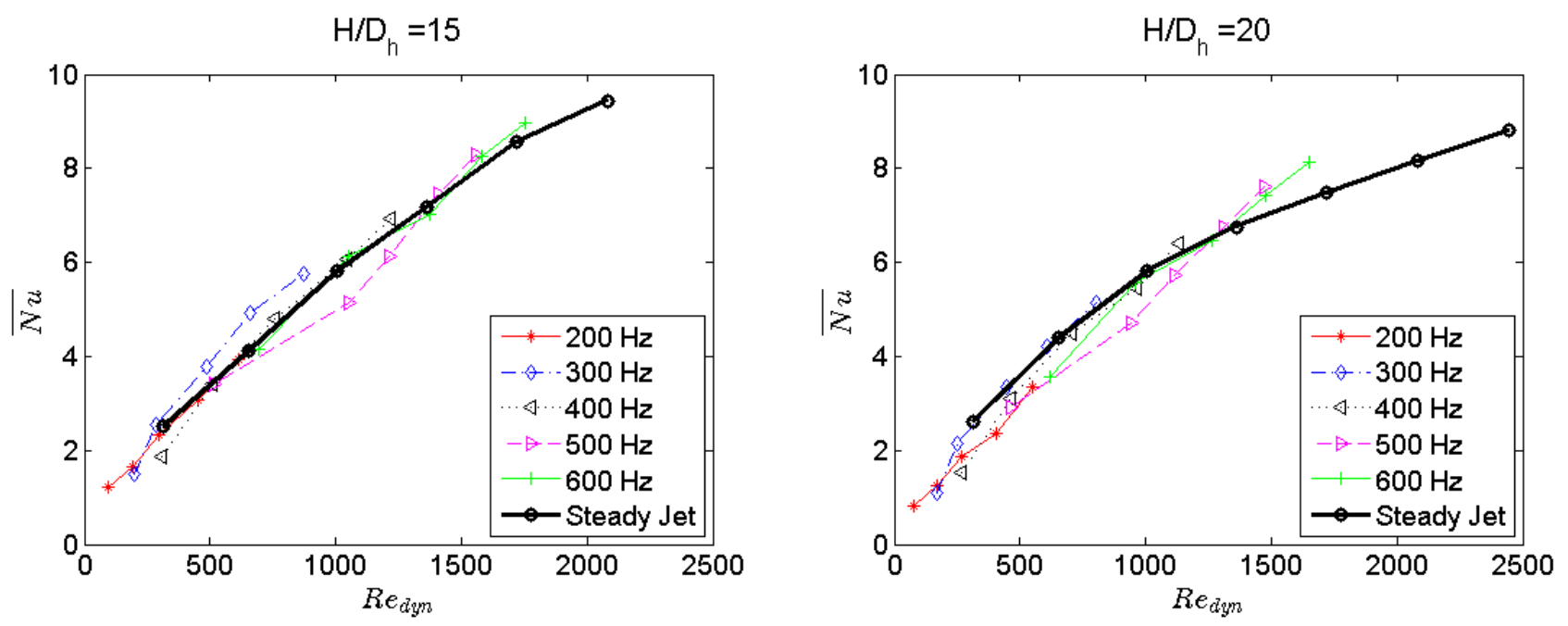

Figure 16. Variation of $\mathrm{Nu}$ number with dynamic $\mathrm{Re}$ number

\section{SUMMARY AND CONCLUSIONS}

This paper reports heat transfer characteristics of single-slot, impinging steady and synthetic jets on a 25.4-mm $\times$ 25.4-mm vertical surface. The experiments were conducted with fixed nozzle width of $1 \mathrm{~mm}$. The parameters varied in the testing were nozzle length ( $4 \mathrm{~mm}, 8 \mathrm{~mm}, 12 \mathrm{~mm}, 15 \mathrm{~mm}), \operatorname{Re}$ number $(100-2,500)$, and dimensionless nozzle-to-plate spacing $\left(\mathrm{H} / \mathrm{D}_{\mathrm{h}}=5,10,15,20\right)$. An 8-mm $\times 1$-mm synthetic jet was also studied with the varied parameters of applied voltage (20-100 V) and driving frequency (200-600 Hz). The synthetic jet instantaneous exit velocities were measured, and a characteristic synthetic jet exit velocity was developed for comparison with the steady jet.

The major conclusions are:

- For both steady and unsteady jets, the heat transfer coefficient on a vertical surface increases with increasing $R e$ number.

- Nozzle-to-plate spacing plays a more significant role on the $N u$ number for steady jets.

- For small nozzle-to-plate spacing $\left(\mathrm{H} / \mathrm{D}_{\mathrm{h}}=5\right)$, the $N u$ number is a strong function of nozzle length. The average $N u$ number correlation, presented in Eq. (7), is not only a function of the $R e$ number but also a function of nozzle length to heater width ratio. This correlation matches the experimental results to within $\pm 10 \%$.

$\circ$ For large nozzle-to-plate spacing $\left(\mathrm{H} / \mathrm{D}_{\mathrm{h}} \geq 10\right)$ and nozzle length larger than $8 \mathrm{~mm}$, the heat transfer coefficient is insensitive to $\mathrm{H} / \mathrm{D}_{\mathrm{h}}$ and nozzle length. The average $N u$ number 
correlation, presented in Eq. (6), is only a function of Re number and nozzle hydraulic diameter. This correlation matches the experimental results to within $\pm 15 \%$.

- For the synthetic jet, the best heat transfer was observed at $\mathrm{H} / \mathrm{D}_{\mathrm{h}}=10$. The synthetic jet exhibited better heat transfer performance than the steady jet with up to a $40 \%$ enhancement in $\mathrm{Nu}$ number. However, the enhancement in $\mathrm{Nu}$ number diminishes with increasing nozzle-to-plate spacing.

- By introducing a dynamic correction term, presented in Eq. (17), the synthetic jet $N u$ number collapses to the steady jet $N u$ number. This means that heat transfer coefficient is not only a function of the $R e$ number, but is also a function of the changing rate of gas velocity.

\section{ACKNOWLEDGMENT}

The authors would like to thank Susan Rogers, Technology Manager for the Power Electronics and Electric Motors task at the Vehicle Technologies Office, U.S. Department of Energy. The authors greatly appreciate contribution from Sreekant Narumanchi and Charles King at the National Renewable Energy Laboratory for their technical guidance and assistance with experimental setup, respectively.

\section{NOMENCLATURE}

$\begin{array}{ll}A & \text { target heater surface area }\left(\mathrm{m}^{2}\right) \\ D_{h} & \text { nozzle hydraulic diameter }(\mathrm{m}) \\ \bar{h} & \text { average heat transfer coefficient on the target heater surface }\left(\mathrm{W} / \mathrm{m}^{2}-\mathrm{K}\right) \\ H & \text { nozzle-to-plate distance }(\mathrm{m}) \\ k & \text { air thermal conductivity }(\mathrm{W} / \mathrm{m}-\mathrm{K}) . \\ L & \text { nozzle length }(\mathrm{m}) \\ N u & \text { Nusselt number } \\ \overline{N u} & \text { average Nusselt number of the target heater surface } \\ N u_{w} & \text { average Nusselt number defined based on nozzle width }\left(N u_{w}=h_{A v g} * W / k\right) \\ Q_{l o s s} & \text { heat loss through the Teflon block }(\mathrm{W}) \\ Q_{\text {surface }} & \text { heat transfer on the target heater surface }(\mathrm{W}) \\ Q_{\text {total }} & \text { total target heater heat consumption }(\mathrm{W}) \\ R e & \text { Reynolds number } \\ R e_{\text {dyn }} & \text { dynamic Reynolds number } \\ \overline{R e}_{\text {SteadyJet }} & \text { steady jet Reynolds number based on the mean gas velocity } \\ R e_{\text {SteadyJet_Max }} & \text { steady jet Reynolds number based on the maximum gas velocity }\end{array}$




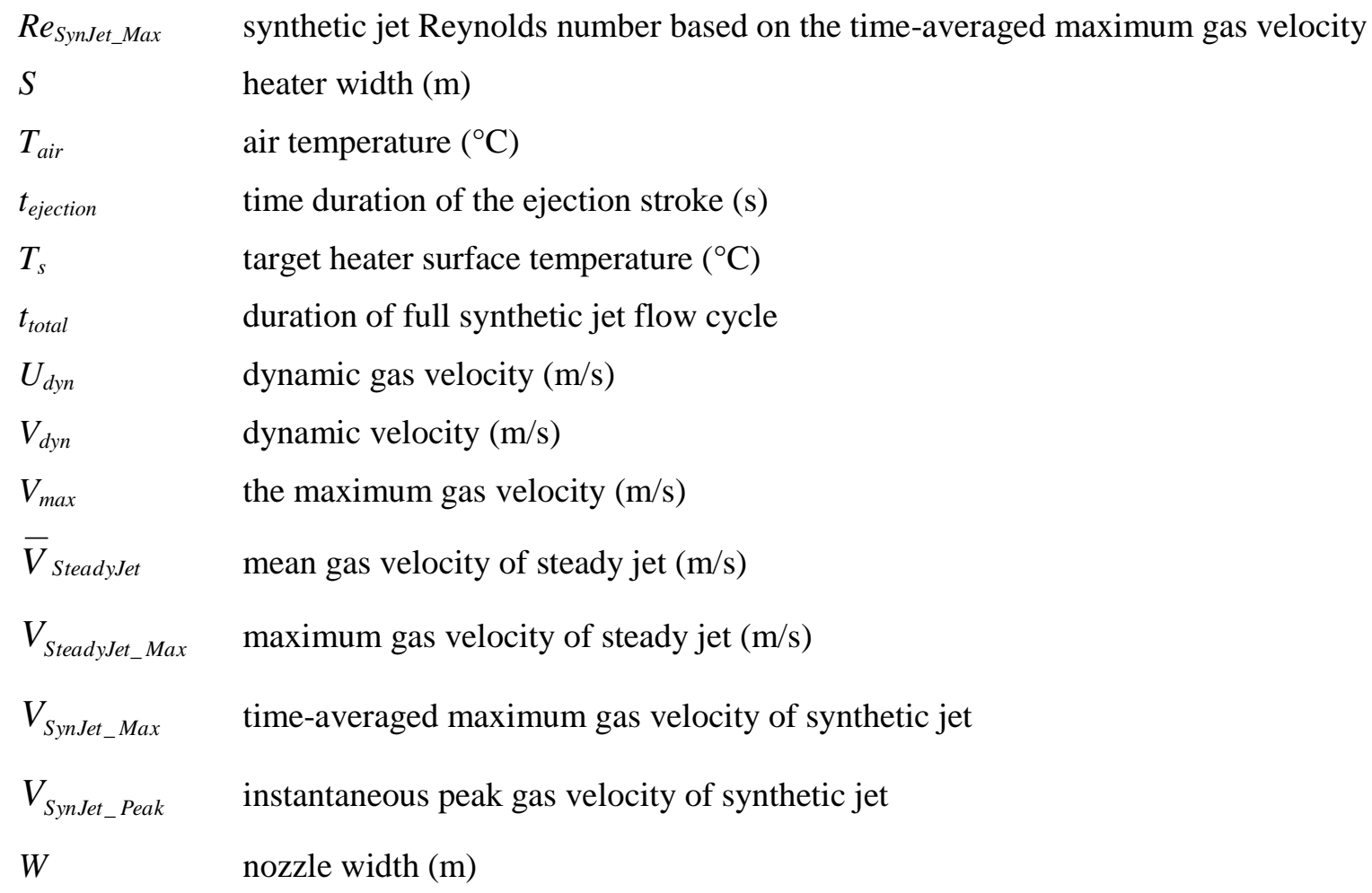

1. H. Martin, Heat and mass transfer between impinging gas jets and solid surface, Advances in Heat Transfer 13 (1977) 1-60.

2. K. Jambunathan, E. Lai, M.A. Moss, B.L. Button, A review of heat transfer data for single circular jet impingement, Int. J. Heat Fluid Flow 13 (2) (1992) 106-115.

3. C. Glynn, D.B. Murray, Jet impinging cooling in microscale, ECI International Conference on Heat Transfer and Fluid Flow in Microscale, Castelvecchio Pascoli, September 25-30, 2005.

4. Z.H. Lin, Y.J. Chou, Y.H. Hung, Heat transfer behaviors of a confined slot jet impingement, Int. J. Heat Mass Transfer 40 (5) (1997) 1095-1107.

5. V. Katti, S.V. Prabhu, Experimental study and theoretical analysis of local heat transfer distribution between smooth flat surface and impinging air jet from a circular straight pipe nozzle, Int. J. Heat Mass Transfer 51(2008) 4480-4495.

6. M. Nirmalkumar, V. Katti, S.V. Prabhu, Local heat transfer distribution on a smooth flat plate impinged by a slot jet, Int. J. Heat Mass Transfer, 54 (2011) 727-738. 
7. B. Sagot, G. Antonini, A. Christgen, F. Buron, Jet impingement heat transfer on a flat plate at a constant wall temperature, Int. J. Thermal Sci. 47 (2008) 1610-1619.

8. D.W. Zhou, S-J. Lee, Forced convective heat transfer with impinging rectangular jets, Int. J. Heat Mass Transfer 50 (2007) 1916-1926.

9. K.S. Choo, Y.J. Youn, S.J. Kim, D.H. Lee, Heat transfer characteristics of a micro-scale impinging slot jet, Int. J. Heat Mass Transfer 52 (2009) 3169-3175.

10. K.S. Choo, S.J. Kim, Air jet impingement heat transfer at low nozzle-to-plate spacings under a fixed pumping power condition, Proceedings of the ASME 2009 Heat Transfer Summer Conference, HT2009-88189.

11. V.P. Schroeder, S.V. Garimella, Heat transfer from a discrete heat source in confined air jet impingement, Proceedings of 11th IHTC, Vol 5, 451-456.

12. J. Lee, S-J. Lee, The effect of nozzle configuration on stagnation region heat transfer enhancement of axisymmetric jet impingement, Int. J. Heat Mass Transfer 43 (2000) 3497-3509.

13. Y. Pan, S. Stevens, B.W. Webb, Effect of nozzle configuration on transport in the stagnation zone of axisymmetric impinging free surface liquid jets: Part 2 - Local heat transfer, ASME J. Heat Transfer 114 (1992) 880-885.

14. L.A. Brignoni, S.V. Garimella, Effects of nozzle-inlet chamfering on pressure drop and heat transfer in confined air jet impingement, Int. J. Heat Mass Transfer 43 (2000) 1133-1139.

15. M.F. Koseoglu, S. Baskaya, The role of jet inlet geometry in impinging jet heat transfer, modeling and experiments, Int. J. Thermal Sci. 49 (2010) 1417-1426.

16. P. Gulati, V. Katti, S.V. Prabhu, Influence of nozzle shape on local heat transfer distribution between flat surface and impinging air jet, Int. J. Thermal Sci. 48 (2009) 602-617.

17. S-J. Lee, J-H. Lee, and D-H. Lee, Local heat transfer measurements from an elliptic jet impinging on a flat plate using liquid crystal, Int. J. Heat Mass Transfer, 37 (1994) 967-976.

18. J. Lee, S-J. Lee, The effect of nozzle aspect ratio on stagnation region heat transfer characteristics of elliptic impinging jet, Int. J. Heat Mass Transfer, 42 (2000) 555-575.

19. M. Arik, J. Petroski, A. Bar-Cohen, M. Demiroglu, Energy efficiency of low form factor cooling devices, ASME International Mechanical Engineering Congress and Exposition, IMECE2007-41275, November 1115, 2007, Seattle, WA.

20. A.L. Minichiello, J.G. Hartley, A. Glezer, W.Z. Black, Thermal management of sealed electronic enclosures using synthetic jet technology, Advances in Electronic Packaging 1997, EEP (19-2), 1809-1812, 1997.

21. Y. Utturkar, M. Arik, and M. Gursoy, An experimental and computational sensitivity analysis of synthetic jet cooling performance, IMECE2006 ASME Int. Mechanical Engineering Congress and Exposition, IMECE2006-13743, Chicago, IL, November 5-10, 2006. 
22. J. Garg, M. Arik, S. Weaver, T. Wetzel, and S. Saddoughi, Advanced localized air cooling with synthetic jets, ASME Journal of Electronics Packaging, Vol. 127, 503-511, 2005.

23. R.H. Dieck, W.G. Steele, and G. Osolsobe, Test uncertainty. ASME PTC 19.1-2005. New York, NY. American Society of Mechanical Engineers.

24. P. Zeng, D.N. Assanis, Unsteady convective heat transfer modeling and application to engine intake manifolds, Proceeding of IMECE 2004, 2004 ASME International Mechanical Engineering Congress and RD\&D Expo, Nov. 13-19, 2004, Anaheim, California, USA, IMECE 2004-60068. 